\title{
Education and Training in Clinical Neuropsychology: Recent Developments and Documents From the Clinical Neuropsychology Synarchy
}

\author{
Glenn Smith, on behalf of the CNS ${ }^{\dagger *}$ \\ Department of Clinical and Health Psychology, University of Florida, Gainesville, FL 32610, USA \\ *Corresponding author at: Department of Clinical and Health Psychology, University of Florida, Gainesville, FL 32610. USA. \\ E-mail address: glennsmith@phhp.ufl.edu \\ Editorial Decision 20 August 2018; Accepted 7 October 2018
}

\begin{abstract}
The Clinical Neuropsychology Synarchy (CNS) interfaces with the American Psychological Association and affiliated organizations to address issues and advances in specialty training. The past several years have seen the development and dissemination of several initiatives pertinent to specialty training. Among these initiatives was the creation of a taxonomy for education and training in clinical neuropsychology. In additional there has been a movement towards competency-based education that has become codified in the APA's new Standards for Accreditation. Calls for competency-based education have also influenced the expectations of the APA's Committee on Recognition of Specialties and Proficiencies in Professional Psychology. As the convener of national clinical neuropsychology organizations the CNS has overseen the development of relevant documents for our specialty. This paper presents three documents critical to training in our field that were developed through the CNS and approved by its member organizations. The first is the Taxonomy for Education and Training in Clinical Neuropsychology. The second is Entry Level Competencies for Clinical Neuropsychology and the third is a distillation of the entry-level competency document for the purpose of identifying competencies to be addressed at the post-doctoral residency level.
\end{abstract}

Keywords: Clinical neuropsychology; education; training; competencies

\section{Introduction}

In the past 6 years the Education Directorate of the American Psychological Association (APA) has been very active in seeking to standardize nomenclature and practices as they pertain to education and training in professional psychology specialties. The APA Education Directorate has taken advantage of the infrastructure that exists (technically outside of the APA) to reach out to the specialties to both seek input and disseminate "standards" to the specialties. Fig. 1 depicts that infrastructure including the place of the Clinical Neuropsychology Synarchy (CNS) within this infrastructure. The initiatives that have emanated from APA's Education Directorate have resulted in three key documents critical to training in our field that were developed through the CNS and approved by its member organizations. The first is the Taxonomy for Education and Training in Clinical Neuropsychology. The second is Entry Level Competencies for Clinical Neuropsychology and the third is a distillation of the entry-level competency document for the purpose of identifying competencies to be addressed at the post-doctoral residency level. Presented below are the roles played by various entities presented in Fig. 1 followed by the text of the three key documents.

\footnotetext{
${ }^{\dagger}$ Organizational representatives to CNS contributing to the development of the documents referenced herein include: Society for Clinical Neuropsychology; Brad Roper, Paula Shear, Jennifer Vasterling, Neil Pliskin, Amy Heffelfinger, Karin McCoy, Robert Seegmiller, Jessica Vassallo. National Academy of Neuropsychology: Laura Lacritz, American Board of Clinical Neuropsychology: Heather Belanger, American Academy of Clinical Neuropsychology: Michelle Braun, Doug Bodin. American Board of Professional Neuropsychology, John Knippa. Association of Post-Doctoral Programs in Clinical Neuropsychology, Doug Bodin. Association of Internship Training in Clinical Neuropsychology, Steve Correa, John Beauvais, Association of Doctoral Education in Clinical Neuropsychology; Maria Schultheis, Association Neuropsychology Students and Trainees; Cady Block, Katie Osborne, Octavio Santos. We would like to acknowledge the contributions of Rus Bauer and Celiane Rey-Casserly to the development of the entry-level competencies.
} 


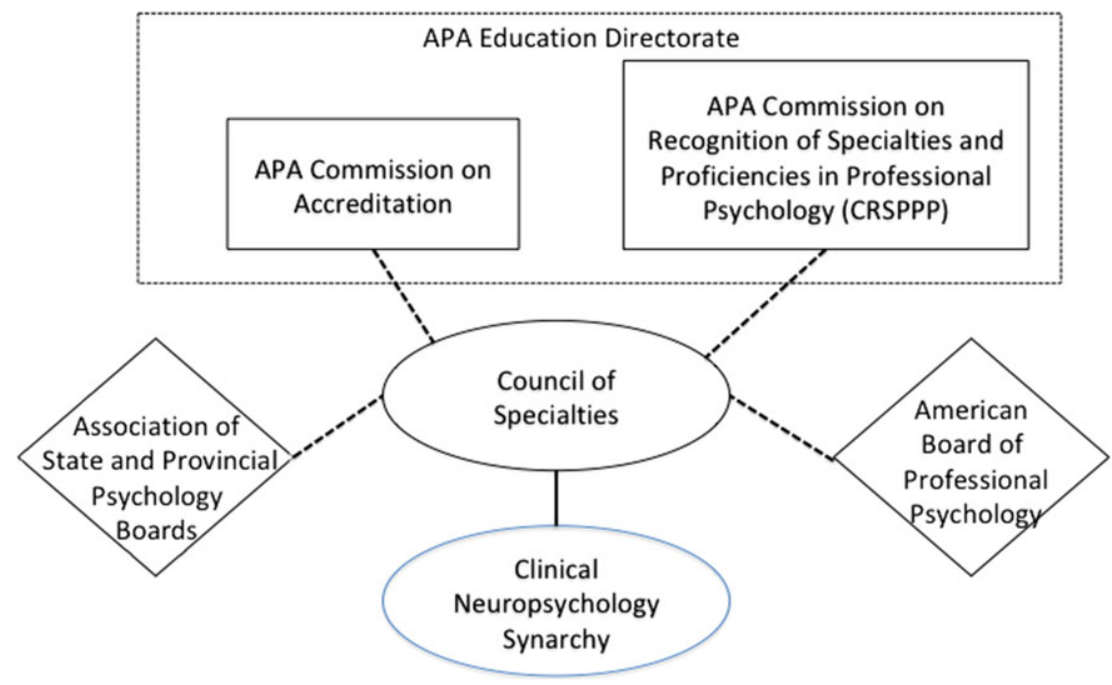

Fig. 1. Reporting relationships among entities involved in specialty training guidelines.

\section{The role of APA Commission on Recognition of Specialties and Proficiencies in Professional Psychology (CRSPPP)}

As suggested by its name, CRSPPP is the organization within the APA that formally recognizes professional psychology specialties. There are currently 15 specialties recognized by CRSPPP. In 2012, CRSPPP published Education and Training Guidelines: A Taxonomy for Education and Training in Professional Psychology Health Service Specialties (APA, 2012). This document was the culmination of efforts by CRSPPP, the Council of Specialties (CoS), the American Board of Professional Psychology (ABPP), the APA Commission on Accreditation (CoA) and others to address the problem reflected in the document's statement of need:

"There has been a growing need for a taxonomy to guide those seeking education and training in a recognized specialty. ${ }^{1}$ Such a taxonomy would also provide a structure for the field in general to facilitate better communication concerning how professional psychologists are educated and trained beyond the broad and general training consistent with accreditation standards (APA, 2009b). Currently there is not consistent use of definitions or terms in the education and training community to describe training opportunities in areas recognized as specialties by APA (APA, 2009a, Section 90-5). For example, in describing training opportunities, education and training departments and programs use a range of terms like area of study, track, or concentration. These terms may refer to the same or to different amounts of course work or practica from department to department or from program to program. Such inconsistency jeopardizes a consistent "truth in advertising" that would be helpful to students as they seek graduate education or to later describe the educational and training opportunities provided in their graduate or postgraduate education."

"Lack of consistency in the use of such terms is also evident across professional organizations and groups whose focus is on education and training in professional psychology. For example, the Association of Psychology Postdoctoral and Internship Centers (APPIC) asks programs to describe the types of training available using the terms major rotation and informal/minor/external rotation, whereas the Committee on Accreditation $(\mathrm{COA})$ uses the phrase areas of emphasis to refer to training opportunities in specialty areas other than the substantive traditional practice areas of clinical, counseling, and school (APA, 2003, IR C-6[a]).”(APA, 2012, p. 4.)

Having laid out a set of common terms and constructs for the taxonomy CRSPPP charged the CoS to obtain from the specialties, definitions of the terms within the taxonomy as they pertained to training in given specialty.

In addition, documentation of the entry-level competencies of that specialty is expected to be part of petitions to CRSPPP for specialty recognition or renewal for each specialty. In anticipation of pursuing specialty recognition renewal in 2017 is was clear that the Houston Conference document (Hannay et al., 1998) needed supplementation to include an enumeration of competencies that aligned with recent competency standards in professional psychology (Kaslow, 2004). Thus a statement of entry level entry-level competencies for clinical neuropsychology was developed, vetted and approved through CNS.

\section{The Role of the APA Commission on Accreditation}

In 2015, the Commission on Accreditation's new Standards of Accreditation (SoA; APA, 2015) were approved by the APA Council of Representatives. These standards went into effect for programs being reviewed after January 7, 2017. These 
standards have been a major impetus for defining and training to competencies in health services psychology. The competency documents provided below in this manuscript represent our specialty's efforts to align with this trend. Of specific import to specialty training, and relevant especially at the post-doctoral residency level, the SoA describes advanced competency levels as follows:

- Level 1: Advanced competencies fundamental to health service psychology

- Level 2: Competencies relevant to the program's aims or area of focus

- Level 3: Competencies that are consistent with a designated specialty

Subsequent to issuing the new standards of accreditation the CoA has seemed to increase its attention to accreditation of post-doctoral training programs. In order to proceed with this the CoA has begun to consider the competencies that should be addressed in post-doctoral training. Thus in the spring of 2017 the CoA, through the CoS, asked the specialties delineate competencies to be consider during the review of post-doctoral training programs seeking specialty accreditation.

\section{The Role of the Council of Specialties}

Specialties in professional psychology recognized CRSPPP are expected to have a specialty council. In fact, the first criterion in a petition for specialty recognition is

"Criterion I. Administrative Organizations. The proposed specialty is represented by a specialty council of one or more organizations that provide systems and structures sufficient to support the organized development of the specialty." (APA, 2011, p. 3)

$\mathrm{CoS}$ is not an official APA committee. CoS does include a liaison from CRSPPP as well as liaisons from other groups such as Association of State and Provincial Boards of Psychology, the American Board of Professional Psychology and the Association of Psychology Graduate Students. CoS advocates for specialty issues within the APA structure through CRSPPP. Similarly when APA encounters issues germane to more than one specialty it will work with and through $\mathrm{CoS}$ to address these cross-specialty issues. Each of the 15 specialty councils sends a representative to the Council of Specialties (www. cospp.org). Generally that representative is the chair of the specialty council.

\section{The Role of the Clinical Neuropsychology Synarchy}

Aside from the broader Clinical, School, and Counseling areas, clinical neuropsychology is the longest recognized specialty in psychology. As such, it maintains one of the most experienced specialty councils. Our council is named the Clinical Neuropsychology Synarchy (synarchy means to govern together and is the antonym of anarchy). Our specialty council retains this old name in recognition of the clinical neuropsychologists who did the heavy lifting that resulted in the recognition of neuropsychology as a specialty in the first place.

The CNS is made up of representatives of the major American clinical neuropsychology organizations. This includes organizations that represent individual clinical neuropsychologists and organizations that represent institutions that are training or credentialing the next generation of clinical neuropsychologists. The member organizations of CNS are listed in Table 1.

It is through the structure depicted in Fig. 1 that the organizations represented in Table 1 responded to APA calls for a specialty-specific education and training standards and documents. In the case of each of three documents presented herein,

Table 1. CNS membership during the development of the documents described herein

\begin{tabular}{llc}
\hline $\begin{array}{l}\text { These organizations can be organized as follows: } \\
\begin{array}{l}\text { Organizations representing individual } \\
\text { neuropsychologists }\end{array}\end{array}$ & Organizations representing training institutions & Organizations engaged in certification \\
\hline Society of Clinical Neuropsychology & $\begin{array}{c}\text { Association of Post-Doctoral Programs in Clinical } \\
\text { Neuropsychology } \\
\text { Association of Internship Training in Clinical } \\
\text { Neuropsychology }\end{array}$ & $\begin{array}{c}\text { American Board of Clinical } \\
\text { Neuropsychology } \\
\text { American Board of Professional } \\
\text { Neuropsychology* }\end{array}$ \\
American Academy of Clinical Neuropsychology & $\begin{array}{c}\text { Association of Doctoral Education in Clinical } \\
\text { Neuropsychology }\end{array}$ & \\
Association of Neuropsychology Students* & &
\end{tabular}

*Liaison. 
the CNS Chair (GES) empaneled subcommittees from CNS membership to respond to requests from CoS. In each case representatives from organizations with a major stake in the document (e.g. ADECN, AITCN, and APPCN for the taxonomy document) volunteered to draft preliminary documents. These documents were then circulated via CNS to all its members for comment and suggested revision. In each case the CNS subcommittee collated and responded to suggested revisions before returning the document to CNS members for a final vote.

The standard for approval of each of the documents presented below was endorsement by a majority of the boards of CNS member organizations. This was necessarily a deliberate and time-consuming process. For example, in took over 2 years from the time of the original request until the taxonomy and entry level competency documents were approved by the full CNS. Following CNS approval, all of these documents have been submitted to CoS and posted on Clinical Neuropsychology's page on the COS website (www.cospp.org/clinical-neuropsychology). Note that the intended audiences for these documents are overlapping but varied. For example, the taxonomy is intended to support standard language used by training directors at different levels of training. The goal is transparency, so that prospective trainees can have clear understanding as to what programs offer. The competency document is also of clear relevance to training directors and trainees but is also meant to inform credentialing organizations. The target audience for the post-doctoral competency document was specifically the APA Commission on Accreditation (CoA), which is evaluating its methods for accreditation at the post-doctoral level. Despite the differing audiences all documents are pertinent to education, training, and credentialing in clinical neuropsychology. The members of CNS felt these three documents should be presented together in this report. The goal of this report is increase awareness of these documents, enhance understanding of their purpose, similarities, differences, and make them more accessible and citable.

\section{Taxonomy for Education and Training in Clinical Neuropsychology}

Through the process described above a taxonomy for clinical neuropsychology was developed by CNS and approved by its members. It is presented in Table 2.

\section{Entry-level Competencies in Clinical Neuropsychology}

The competency document developed by CNS and approved by its members included a (1) preamble and an (2) extensive set of tables (Tables 3-10) enumerating the foundational and functional specialty competencies. The two-part document (preamble and competency tables) was included in the clinical neuropsychology specialty renewal petition submitted to CRSPPP in December, 2016. It is presented below.

\section{Preamble}

Scope. The present document represents an inter-organizational effort promoted and moderated by the Clinical Neuropsychology Synarchy to delineate entry-level competences for clinical neuropsychology. It is important to emphasize that enumeration of entry-level competencies does not alter Houston Conference Guidelines (HCG). The HCG continue to describe the process of specialty training in clinical neuropsychology. Rather, this document describes the expected outcomes from following the HCG. These outcomes are enumerated in terms of practicable and measurable competencies. The HCG specify that rigorous, extensive and cumulative training in clinical neuropsychology takes place at the doctoral, internship, and postdoctoral levels but allows for flexibility regarding the level at which different trainees may achieve knowledge and skills. Similarly this document presents entry-level competencies cognizant that no single level of training imparts all competencies and that individuals may acquire these competencies in a varied fashion.

Background. The specialty training guidelines for clinical neuropsychology delineated in the Houston Conference statement, (Hannay et al., 1998a) have served the field well for almost 20 years. They have served as a specific but flexible guide for how to train in the field. A survey conducted in 2010 by the Inter-organizational Steering Committee on Education and Training (ISET) showed that Houston Conference guidelines have been widely adopted by training programs. Furthermore, those receiving training consistent with the guidelines rated themselves as being well prepared for practice (Sweet, Perry, Ruff, Shear, \& Guidotti Breting, 2012). As such, the ISET saw no need for a wholesale revision of training guidelines, but acknowledged that a broadening of the field and new technologies may prompt the need for updates.

While Houston Conference Guidelines have been invaluable in specifying training structure they were less explicit in describing training goals, i.e., what the training structures described in the Houston Conference Guidelines should deliver. In 
Table 2. Taxonomy for education and training in clinical neuropsychology

\begin{tabular}{|c|c|c|c|c|}
\hline & Doctoral $^{\mathrm{a}}$ & Internship $^{a}$ & Postdoctoral $^{\mathrm{a}}$ & Post-licensure $^{\mathrm{a}}$ \\
\hline Emphasis & $\begin{array}{l}\text { 1) Two neuropsychology courses } \\
\text { AND 2) two clinical } \\
\text { neuropsychology practica }^{\mathrm{c}}\end{array}$ & $\begin{array}{l}>30 \% \text { and }<50 \% \text { of experience in } \\
\text { clinical neuropsychology supervised } \\
\text { by a clinical neuropsychologist. }\end{array}$ & N/A & N/A \\
\hline Experience & $\begin{array}{l}\text { 1) One or two neuropsychology } \\
\text { course(s) })^{\text {b AND } 2) \text { one clinical }} \\
\text { neuropsychology practicum }^{c}\end{array}$ & $\begin{array}{l}>10 \% \text { and }<30 \% \text { of supervised } \\
\text { experience in clinical } \\
\text { neuropsychology }\end{array}$ & N/A & N/A \\
\hline
\end{tabular}

Note: As per APA guidelines all supervision in clinical neuropsychology must be provided by persons with competencies in clinical neuropsychology, aka, a clinical neuropsychologist.

${ }^{\text {a }}$ At the doctoral and internship training levels, it is recognized that all programs must meet the broad and general requirements for accreditation by the American Psychological Association (APA) or the Canadian Psychological Association (CPA). At the postdoctoral training level, it is recognized that the Major Area of Study is consistent with training standards for specialty accreditation in clinical neuropsychology through the APA. Regarding all levels of training, guidelines for specialty education and training in clinical neuropsychology are specified in the Houston Conference Guidelines, Hannay et al. (1998).

${ }^{\mathrm{b}}$ To be a neuropsychology course, the course content must prominently address areas outlined in the Houston Conference Guidelines policy statement, Section VI.3 and Section VI.4. Additionally, the number of courses listed above assumes that courses are 3 credit hours each, within a semester system. As such, the Major Area of Study would require a minimum of 9 semester credit hours or 13.5 quarter credit hours, the Emphasis would require a minimum of 6 semester credit hours or 9 quarter credit hours, and the Experience and the Exposure would require a minimum of 3 semester credit hours or 4.5 quarter credit hours.

${ }^{\mathrm{c}}$ Defined by practicum experience for equivalent of one academic year (e.g. 9 months, in semester or quarter systems) consisting of supervised training for at least $8 \mathrm{hr}$ per week, with at least $50 \%$ clinical contact with patients in the provision of neuropsychological services.

${ }^{\mathrm{d} A d d i t i o n a l ~ t r a i n i n g ~ e x p e r i e n c e s ~ c a n ~ a l s o ~ i n c l u d e, ~ b u t ~ a r e ~ n o t ~ l i m i t e d ~ t o, ~ r e s e a r c h ~ e x p e r i e n c e s, ~ l a b ~ m e e t i n g s, ~ b r o w n ~ b a g s, ~ l e c t u r e / c o l l o q u i a ~ s e r i e s, ~ g r a n d ~}$ rounds, etc. and should be consistent with the guidelines for specialty education and training that are specified in the Houston Conference policy statement.

${ }^{\mathrm{e}}$ Knowledge base. Clinical neuropsychologists possess the following knowledge. This core knowledge may be acquired through multiple pathways, not limited to courses, and may come through other documentable didactic methods.1. Generic Psychology Core: A. Statistics and methodology B. Learning, cognition and perception C. Social psychology and personality D. Biological basis of behavior E. Life span development F. History. G. Cultural and individual differences and diversity 2. Generic Clinical Core: A. Psychopathology B. Psychometric theory C. Interview and assessment techniques D. Intervention techniques E. Professional ethics 3. Foundations for the study of brain-behavior relationships: A. Functional neuroanatomy B. Neurological and related disorders including their etiology, pathology, course and treatment C. Non-neurologic conditions affecting CNS functioning D. Neuroimaging and other neurodiagnostic techniques E. Neurochemistry of behavior (e.g., psychopharmacology) F. Neuropsychology of behavior 4. Foundations for the practice of clinical neuropsychology: A. Specialized neuropsychological assessment techniques B. Specialized Neuropsychological intervention techniques C. Research design and analysis in neuropsychology D. Professional issues and ethics in neuropsychology E. Practical implications of neuropsychological conditions.

${ }^{\mathrm{f}}$ Skills. Clinical neuropsychologists possess the following generic clinical skills and skills in clinical neuropsychology. These core skills may be acquired through multiple pathways, not limited to courses, and may come through other documentable didactic methods. Domains of skills and examples are: 1 . Assessment: Information gathering. History taking. Selection of tests and measures. Administration of tests and measures. Interpretation and diagnosis. Treatment planning. Report writing. Provision of feedback. Recognition of multicultural issues. 2. Treatment and Interventions: Identification of intervention targets. Specification of intervention needs. Formulation of an intervention plan. Implementation of the plan. Monitoring and adjustment to the plan as needed. Assessment of outcome. Recognition of multicultural issues. 3. Consultation (patients, families, medical colleagues, agencies, etc.): A. Effective basic communication (e.g. listening, explaining, negotiating) B. Determination and clarification of referral issues C. Education of referral sources regarding neuropsychological services (strengths and limitations) E. Communication of evaluation results and recommendations F. Education of patients and families regarding services and disorder(s) 4. Research: Selection of appropriate research topics. Review of relevant literature. Design of research. Execution of research. Monitoring of progress. Evaluation of outcome. Communication of results. 5. Teaching and Supervision: Methods of effective teaching. Plan and design of courses and curriculums. Use of effective educational technologies. Use of effective supervision methodologies (assessment, intervention, and research).

${ }^{\mathrm{g}}$ The residency experience must occur on at least a half-time basis.

the time since those guidelines were developed there has been increasing emphasis on defining competencies for professional practice, including within medicine (Epstein \& Hundert, 2002; Williams et al., 2010) and psychology (Health Service Psychology Education Collaborative, 2013; Kaslow, 2004; Kaslow, et al., 2004; Roberts, Borden, \& Christiansen, 2005; Rodolfa et al., 2005). As such, it has become increasingly important to express professional activities in terms of practice 
Table 3. Foundational competencies unique to clinical neuropsychology but common across functional domains

\begin{tabular}{|c|c|}
\hline Cluster/Foundational Domain & Competency encompassed by domain \\
\hline Evidence-Based Practice & $\begin{array}{l}\text { - Understands key signs and symptoms of disease processes relevant to practice and how patient characteristics (e.g., } \\
\text { demographic factors, comorbidities) affect their expression. } \\
\text { - Understands age-related changes in brain functioning and behavior across the lifespan. } \\
\text { - Understands the scientific basis for assessment strategy, including test selection, use of appropriate normative } \\
\text { standards, psychometric and operating characteristics, and test limitations. } \\
\text { - Understands patterns of incidence, prevalence (i.e., base-rate), and natural course of conditions of interest in } \\
\text { neuropsychology } \\
\text { - Appreciates decision-making strategies and their applications in differential diagnosis. } \\
\text { - Knows the scientific basis for diagnostic conclusions across a range of neuropsychological disorders. } \\
\text { - Incorporates and uses outcome research in neuropsychology in guiding assessments and formulating interventions, } \\
\text { integrating patient and contextual factors. } \\
\text { - Applies key components of evidence-based practice (i.e., best evidence, clinical expertise, and patient characteristics/ } \\
\text { - culture/values) in selecting appropriate assessment and intervention approaches. } \\
\text { - Applies information technology to assess and evaluate best evidence to guide practice. }\end{array}$ \\
\hline Individual and Cultural Diversity & $\begin{array}{l}\text { - Integrates knowledge of diversity issues in neuropsychological assessment, research, treatment, and consultation (e.g. } \\
\text { health disparities, language differences, educational level, cultural context, literacy, individual differences). } \\
\text { - Understands and appreciates how cultural, linguistic, disability, and other demographic/socioeconomic factors affect } \\
\text { the process and outcomes of neuropsychological assessments and the application of normative data and interpretations } \\
\text { in specific populations. }\end{array}$ \\
\hline $\begin{array}{l}\text { Ethical, Legal Standards and } \\
\quad \text { Policy }\end{array}$ & $\begin{array}{l}\text { - Applies ethical concepts across a range of settings; demonstrates awareness of legal issues relevant to the professional } \\
\text { activities of clinical neuropsychologists across settings, including healthcare, research, school, military/veteran, } \\
\text { industry, and forensic (e.g., criminal, personal injury, disability determination, fitness for duty, etc.). } \\
\text { - Understands specific ethical and legal issues that are relevant to neuropsychologist's activities across settings, } \\
\text { including informed consent, third party assessments, use of technicians/psychometrists, third party observers, } \\
\text { disclosure of neuropsychological test data, and test security. }\end{array}$ \\
\hline Professional Identity & $\begin{array}{l}\text { - Demonstrates professional identity as a clinical neuropsychologist; understands the unique contributions of } \\
\text { neuropsychology to different educational, healthcare, and forensic/legal contexts. } \\
\text { - Demonstrates awareness of the roles of clinical neuropsychologists, and how those roles vary across settings (e.g., } \\
\text { practice, research, training, etc.) and assessment/intervention contexts. }\end{array}$ \\
\hline Interdisciplinary Systems & $\begin{array}{l}\text { - Demonstrates knowledge of key issues and concepts in related disciplines (e.g., neurology, psychiatry, } \\
\text { neuroradiology, rehabilitation, education) the ability to communicate and interact knowledgeably with professionals } \\
\text { across these disciplines. } \\
\text { - Understands the roles of other professionals with regard to patient care and integrates the perspectives of related } \\
\text { disciplines into their case conceptualizations. } \\
\text { - Makes appropriate referrals to other health professionals as part of treatment planning. } \\
\text { - Is able to work as a member of interprofessional teams and collaborate with other professionals to contribute } \\
\text { neuropsychological information to overall team diagnostic formulation, planning, and intervention. }\end{array}$ \\
\hline
\end{tabular}

competencies. Clinical neuropsychology has yet to delineate detailed competencies for entry-level practice. At the point of its fourth petition for specialty status it behooves clinical neuropsychology to do so.

Because Houston Conference guidelines specify that a two-year postdoctoral residency serves as the culminating prerequisite for entry into practice in the specialty, defining entry-level competencies de facto defines the competencies expected of trainees at the completion of the postdoctoral residency.

Enumeration of these entry-level competencies will have the following benefits: 
Table 4. Functional competencies: assessment

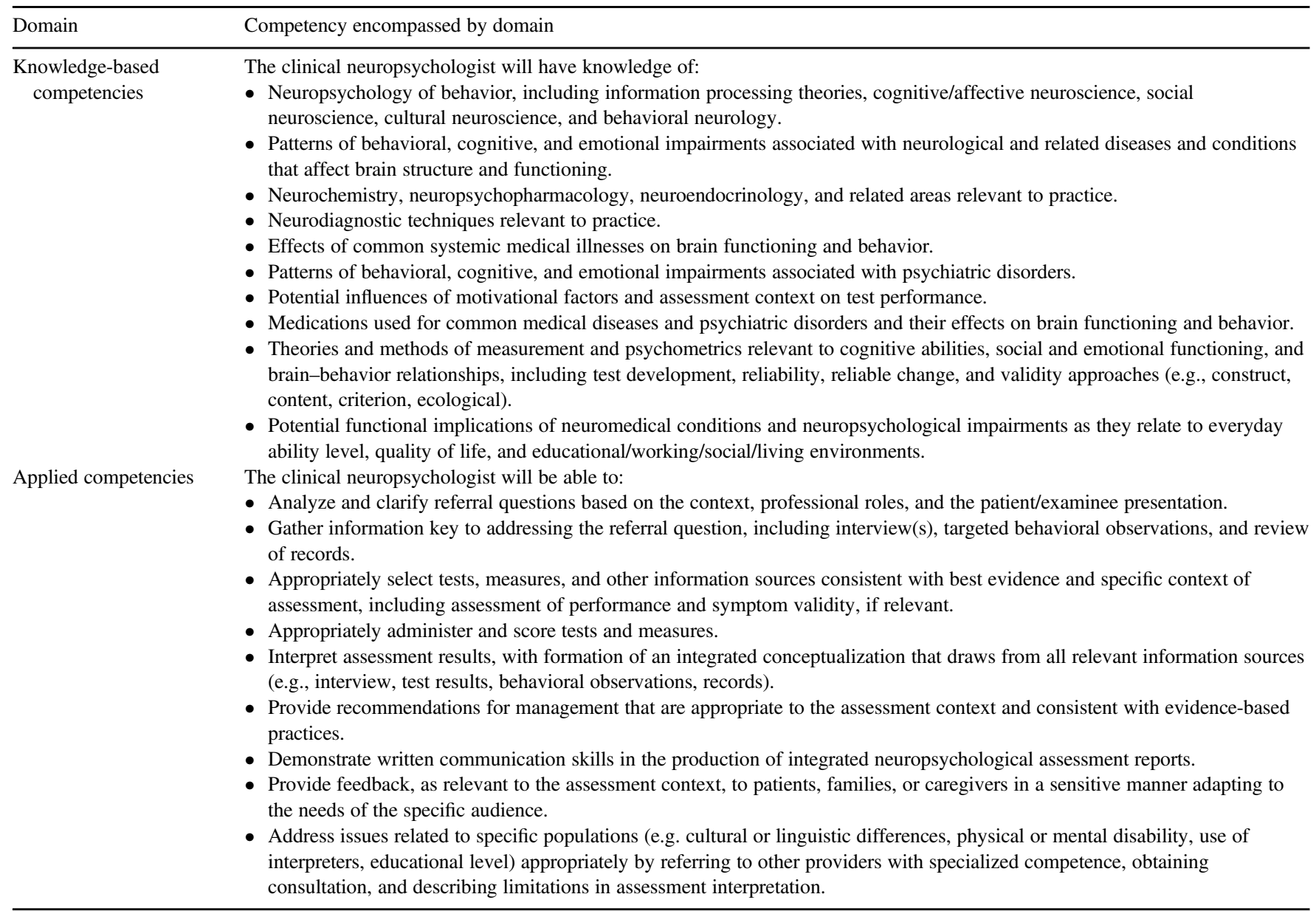

- Serve as a helpful resource for training programs, especially programs seeking accreditation at the postdoctoral level. Common materials could also be developed that greatly streamline the process of initiating and maintaining accreditation.

- Enhance the process of specialty credentialing of clinical neuropsychologists.

- Provide a framework for more senior clinical neuropsychologists to consider continuing education opportunities.

- Serve to identify the unique knowledge, skills, and abilities of clinical neuropsychologists that will enhance broad advocacy efforts in a changing healthcare environment.

Process. An initial effort to develop entry-level competencies was made by Rey-Casserly, Roper, and Bauer (2012) in Professional Psychology: Research and Practice. Those competencies were reviewed in detail by a task force established by the Clinical Neuropsychology Synarchy (CNS) which included Glenn Smith, CNS Chair, Neil Pliskin, SCN President, Paula Shear, SCN Past-President, Celiane Rey-Casserly, past Chair of the APA Committee on Accreditation, and Brad Roper, Chair of the SCN Education Advisory Committee, resulting in several wording changes from the original article. This first revision of the document was forwarded to the all CNS members on 1/4/2015 inviting comment. Initial reactions to the competencies were discussed at the CNS meeting in Denver in February 2015. Organizations then provided feedback in earnest over the course of the ensuing year. These comments were coalesced by Dr. Roper and discussed at the CNS annual meeting in Boston in February of 2016. At that meeting a subcommittee was formed to finalize integration of member organizations contributions into the competency documents. A second revision was submitted to all member organizations in the spring of 2016 requesting that the organizations affirm the committee's accommodation of their input. The final document was included along with our petition for continued recognition as a specialty area to the Commission for the Recognition of Specialties and Proficiencies in Professional Psychology (CRSPPP) in December 2016. 
Table 5. Functional competencies: intervention

\begin{tabular}{ll}
\hline Domain & Competency encompassed by domain \\
\hline Knowledge-based & The clinical neuropsychologist will have knowledge of: \\
competencies & - Evidenced-based intervention practices to address cognitive and behavioral problems present in different clinical populations. \\
- Theoretical and procedural bases of intervention methods appropriate to address disorders of language, attention, learning and \\
memory, executive skills, problem solving, perceptual processing, sensorimotor functioning, and psychological/emotional \\
adjustment. \\
- How complex neurobehavioral disorders (e.g., aphasia, anosognosia, neuropsychiatric illness) and sociocultural factors can \\
affect the applicability of interventions. \\
- How to promote cognitive health with patients through activities such as physical and cognitive exercise, stress management, \\
and sleep hygiene. \\
- Empirically supported interventions provided by psychologists and other mental and behavioral health professionals. \\
The clinical neuropsychologist will be able to: \\
- Identify targets of interventions and specify intervention needs. \\
- Employ assessment and provision of feedback for therapeutic benefit. \\
- Identify potential barriers to intervention and adapt interventions to minimize such barriers. \\
- Develop and implement treatment plans that address neuropsychological deficits while accounting for patient preferences, \\
individual differences, and social cultural context. \\
- Implement evidence-based interventions in neuropsychological disorders. \\
- Independently evaluate the effectiveness of interventions employing appropriate assessment and outcome measurement \\
- Strategies.
\end{tabular}

Table 6: Functional competencies: consultation

\begin{tabular}{ll}
\hline Domain & Competency encompassed by domain \\
\hline Knowledge-based & The clinical neuropsychologist will have knowledge of: \\
competencies & - Professional roles and expectations of a consulting clinical neuropsychologist specific to each setting. \\
& - Relevant literatures on the roles of neuropsychologists in consultation settings. \\
- Appropriate and contextually sensitive methods of consultation. & The clinical neuropsychologist will be able to: \\
- Determine and clarify referral issues. \\
- Educate referral sources regarding the utility and relevance of neuropsychological services. \\
- Communicate findings from consultation activities effectively and efficiently. \\
- Provide effective assessment feedback and articulate appropriate recommendations in language appropriate for the audience. \\
- Provide effective consultation services within common settings and contexts in clinical neuropsychology practice. \\
- Communicate scientific findings within clinical neuropsychology in a manner that is relevant to the consultation setting and \\
- understandable to the recipient. \\
Provide consultation in clinical research regarding brain-behavior relationships and appropriate neurobehavioral assessment \\
strategies and tools.
\end{tabular}

Table 7. Functional competencies: research/evaluation

\begin{tabular}{ll}
\hline Domain & Competency encompassed by domain \\
\hline $\begin{array}{l}\text { Knowledge-based } \\
\text { competencies }\end{array}$ & The clinical neuropsychologist will have knowledge of: \\
& - The scientific method in generating neuropsychological knowledge and evaluating findings related to neuropsychological \\
& techniques, brain-behavior relationships, assessment strategies, and interventions. \\
& - Research design and analysis relevant to clinical neuropsychological science and practice. \\
& - The wide array of factors that mediate and modulate behavior and their implications for neuropsychological and related \\
& research. \\
Applied competencies & The clinical neuropsychologist will be able to: \\
& - Select research topics and perform literature reviews effectively. \\
& - Demonstrate skills in conceptualizing, implementing, and interpreting research design and statistical analysis. \\
& - Perform research activities, monitoring of progress, and evaluation of outcomes accurately and effectively. \\
& - Communicate research findings effectively.
\end{tabular}


Table 8. Functional competencies: teaching/supervision

\begin{tabular}{ll}
\hline Domain & Competency encompassed by domain \\
\hline Knowledge-based & The clinical neuropsychologist will have knowledge of: \\
competencies & - Supervision theories, methods, and practices in professional psychology and clinical neuropsychology. \\
- Developmental stages in training that may impact the acquisition of clinical neuropsychology knowledge and skills. \\
- Ethical issues and state requirements relevant to teaching and supervision \\
The clinical neuropsychologist will be able to: \\
- Provide effective teaching activities, presenting materials in an organized manner that is appropriate to the needs of the \\
- audience. \\
- Provide effective training to psychology trainees in the foundations of assessment, psychometric theory, and the administration \\
and scoring procedures for tests and measures employed in clinical neuropsychology practice. \\
- Provide effective training in developing and asserting professional identity and role as a clinical neuropsychologist. \\
- Provide effective training in neuropsychological interviewing, test interpretation, case conceptualization, and the development \\
- Provide effective training in treatment planning and the provision of feedback. \\
- Demonstrate sensitivity to individual and cultural differences in supervisory contexts.
\end{tabular}

Table 9. Functional competencies: management/administration

\begin{tabular}{ll}
\hline Domain & Competency encompassed by domain \\
\hline $\begin{array}{l}\text { Knowledge-based } \\
\text { competencies }\end{array}$ & The clinical neuropsychologist will have knowledge of: \\
& - Administrative structures of practice settings relevant to neuropsychology. \\
& - Common administrative and business practices needed to address prevalent assessment and consultation issues in \\
& neuropsychology practice (e.g., referral patterns, coding, billing, documentation). \\
Applied competencies & - Methods and procedures for outcome assessment, program evaluation, and research in neuropsychology. \\
& The clinical neuropsychologist will be able to: \\
& - Function effectively within administrative systems, educating others about role of neuropsychology and supporting structures \\
& - Imith the goal of improving access to needed services. \\
& to care, funding). \\
- Train and supervise technicians/psychometrists and monitor their skills following regulatory, ethical and legal standards.
\end{tabular}

Table 10. Functional competencies: advocacy

\begin{tabular}{ll}
\hline Domain & Competency encompassed by domain \\
\hline $\begin{array}{l}\text { Knowledge-based } \\
\text { competencies }\end{array}$ & The clinical neuropsychologist will have knowledge of: \\
Applied competencies & - Regulatory and policy initiatives that can affect provision of neuropsychology services and access to care. \\
& The clinical neuropsychologist will be able to: \\
& - Apply scientific knowledge and skills in neuropsychology to advocate for needs of individuals/groups across systems and to \\
& advocate for equity and access to quality care. \\
& - Collaborate with psychologists and other professionals to advocate for the profession and the specialty of neuropsychology. \\
& - Educate the public about the nature and value of neuropsychology in healthcare. \\
\hline
\end{tabular}

Structure. The competencies are organized following recent developments in the classification of competencies into seven foundational competencies that cross multiple areas of practice (Table 1), and six functional competencies pertaining to specific domains of practice (Tables 2-7). These specific competencies in clinical neuropsychology build on foundational and functional competencies attained in professional psychology doctoral training, in many case providing the describing the application of generic health service psychology competencies (Health Service Psychology Education Collaborative, 2013; Kaslow, 2004; Kaslow, et al., 2004; Roberts et al., 2005; Rodolfa et al., 2005) in the field of clinical neuropsychology. The functional competencies are organized into elements that are knowledge based and elements that are skill based. Clinical neuropsychologists will not employ or demonstrate all competencies equally over the course of their careers. Some neuropsychologists may focus on assessment to the exclusion of intervention. Some private practitioners will do little teaching. However at entry into the field it is expected that they will possess all competencies and be able to demonstrate a preponderance of the competency elements listed in the tables.

Measurement. Consistent with Houston Conference Guidelines (HCG), the entry level for practice begins after completion of an APA-approved doctoral training program, APA-approved internship and a two-year postdoctoral residency. Each level of 
training already incorporates its own forms of interval assessments that are relevant to the competencies described herein. These start with candidate evaluations leading to graduate school admission, evolves through course exams and grades, qualifying exams, dissertation defenses, practica, internship, and post-doc supervisors ratings and culminates via passing written, practice sample, and oral board examinations. However, the enumeration of competencies will undoubtedly spark interest in developing comprehensive, level spanning systems of measuring and tracking trainee progress. Although assessing competency is not part of the current effort, programs and/or organizations may find consensus-based entry-level competencies helpful in developing such systems for their own use.

\section{Competencies at the Post-Doctoral Residency Level}

In December of 2016, CoA sent a request to CoS to direct a project to identify and operationalize the specialty-specific competency domains that will be required of postdoctoral residency programs seeking APA accreditation. In turn, the CoS requested that each specialty council provide to $\operatorname{CoS}$ by July 1, 2017, specialty-specific, essential competencies in 16 competency domains. These domains are based upon ABPP competencies and also include of APA-CoA competencies:

- Integration of science and practice (note: an APA-CoA required competency)

- Ethical and Legal Standards/Policy

- Individual and Cultural Diversity

- Professionalism (professional values attitudes and behavior)

- Reflective practice/self-assessment, self-care

- Scientific knowledge and methods

- Interdisciplinary Systems

- Relationships

- Evidence-based Practice

- Assessment

- Intervention Consultation

- Research/Evaluation

- Supervision

- Teaching

- Management/Administration

- Advocacy

The competency domains Integration of Science and Practice, Ethical and Legal Standards, and Individual and Cultural Diversity are required for all postdoctoral residencies regardless of specialty. Specialties with competencies in any of the other 12 domains, where asked to consider which of those domains should be required during postdoctoral residency training in that specialty.

Specialty councils were asked to provide domain elements, operationalized in a specialty-specific fashion that are observable and easily evaluated. CoA plans to use these competency statements to populate the self-study instructions for postdoctoral residency programs undergoing review for accreditation in a given specialty.

CNS again empaneled a group of key stakeholders. The workgroup was led by Brad L. Roper, Ph.D., ABPP-CN (CoChair, Memphis VA Medical Center), and Amy Heffelfinger, Ph.D., ABPP-CN (Co-Chair, Medical College of Wisconsin). These leaders created a workgroup composed of five training directors drawn from the 25 postdoctoral programs in clinical neuropsychology that were APA-accredited at the time. In selecting workgroup members, consideration was made regarding proportion of representation from VA-based programs, DoD-based programs, academic medical centers and programs with pediatric neuropsychology subspecialty training. In addition to the chairs the workgroup included Karin J.M. McCoy, Ph.D., ABPP-CN (South Texas Veterans Health Care System), Robert A. Seegmiller, Ph.D., ABPP-CN (San Antonio Military Medical Center), and Jessica L. Vassallo, Ph.D., ABPP-CN (James A. Haley Veterans Hospital).

The CoA requires that all postdoctoral programs train and evaluate residents as specified in the Standards of Accreditation (SoA) and Implementing Regulation (IR) C-9P "Profession-Wide Competencies:" This includes competencies in:

- Integration of Science and Practice

- Ethical and Legal Standards

- Individual and Cultural Diversity 
In addition to meeting IR C-9P, specialties may include additional elements of the above competencies that are unique to their specialty. In constructing the competencies, the CoS requested that specialties select from the list below:

- Professionalism (professional values attitudes and behavior)

- Reflective practice/self-assessment, self-care

- Scientific knowledge and methods

- Interdisciplinary Systems

- Relationships

- Evidence-based Practice

- Assessment

The specialty specific competencies to be address by post-doctoral residencies are listed in Tables 11 and 12 . At the time of drafting of this manuscript the nominated competences for post-doctoral training in clinical neuropsychology were still under review from the CoA.

\section{Future Directions and Conclusion}

\section{Assessing Competence}

As noted in the entry-level competencies preamble, enumerating competencies for a field has limited utility unless these competencies can assessed to be present or absent in individual practitioners. Establishing competence is of course a key function of credentialing organizations such as the American Board of Clinical Neuropsychology or the American Board of Professional Neuropsychology. In fact, at the time of the vote to approve the entry-level competency document there was already tight alignment between the document and those competencies included in the board guidelines and procedures that undergird the examination process. However, the capacity to conduct interim assessments of competencies throughout the training sequence will enable more effective and personalized training. Groups such as the APPCN are currently developing tools and methods for such interim assessment of competency acquisition.

\section{Subspecialty Competency}

Clinical neuropsychology has also led the specialties in consider how to incorporate subspecialty practice. In 2014 pediatric neuropsychology became the first subspecialty area with an existing specialty area to be formally recognized by ABPP. It goes without saying that his subspecialty area has both unique and common competencies relative to the larger specialty. However, to date competency documents do not incorporate, reflect, or distinguish subspecialty issues. There is surely a need for this development in the future.

\section{Evolution}

The Houston Guidelines (Hannay et al., 1998) were published twenty years ago. In the opinion of many, these guidelines served the field very well. It seems appropriate that in this 20th anniversary year additional documents pertinent to education

Table 11. Competencies, standards of accreditation level, and number of elements

\begin{tabular}{llc}
\hline Competency & Level & Elements \\
\hline Integration of Science and Practice & 1 & 4 \\
Ethical and Legal Standards/Policy & 1 & 4 \\
Individual and Cultural Diversity & 1 & 3 \\
Professional Identity \& Relationships/Self-Reflective Practice & 3 & 5 \\
Interdisciplinary Systems/Consultation & 3 & 2 \\
Assessment & 3 & 3 \\
Intervention & 3 & 3 \\
Research & 3 & 2 \\
Teaching/Supervision/Mentoring & 3 & \\
Management/Administration & 3 & \\
Total Elements & & 2 \\
\hline
\end{tabular}


Table 12. Competencies and elements

Integration of Science and Practice (Level 1)

- Maintain currency of knowledge and skills in clinical neuropsychology practice, using scientific literature, seminars, conferences, training sessions, and/or other evidence-based resources.

- Demonstrate and utilize knowledge in the following foundational areas, including:

o the neuropsychology of behavior, including information processing theories, cognitive/affective neuroscience, behavioral neurology, and lifespan neuropsychology.

o additional areas as relevant to practice, especially neuroanatomy, neural systems, brain development, and neuropathology.

- Demonstrate and utilize knowledge in the following key areas, including:

o theories and methods of measurement and psychometrics relevant to brain-behavior relationships, cognitive abilities, social and emotional functioning, performance/symptom validity, test development, reliability, validity, and reliable change;

o scientific basis of assessment, including test selection, use of appropriate normative standards, and test limitations;

o patterns of behavioral, cognitive, and emotional impairments associated with neurological, psychiatric, and general medical diseases and conditions which affect brain structure and functioning;

o patterns of incidence, prevalence (i.e., base-rate), natural course, and key signs/symptoms of disease processes for conditions of interest in neuropsychology;

o the potential functional implications of neuromedical conditions, psychiatric conditions, and neuropsychological impairments as they relate to everyday ability level, quality of life, and educational/working/social/living environments.

- Apply key components of evidence-based practice (i.e., best evidence, clinical expertise, and patient characteristics/culture/values) in selecting appropriate assessment, intervention approaches, recommendations, and supervision methods, and when engaging in consultation with other disciplines.

Ethical and Legal Standards/Policy (Level 1)

- Are knowledgeable of, and consistently act in accordance with,

o the current version of the APA Ethical Principles of Psychologists and Code of Conduct;

o relevant laws, statutes, regulations, rules, and policies governing the practice of clinical neuropsychology at the organizational, local, state, regional, and federal levels;

o relevant professional standards and guidelines.

- Are conversant with ethical and legal issues relevant to psychologists and neuropsychologists' activities across settings, including informed consent, provider roles and relationships with patients/examinees, third party assessments, use of technicians/psychometrists, third party observers, disclosure of neuropsychological test data, test security, and assessment of performance/symptom validity.

- Recognize ethical dilemmas as they arise, apply ethical decision-making processes to resolve dilemmas, and utilize professional and legal consultation as appropriate.

- Conduct self in an ethical manner in all professional activities.

Individual and Cultural Diversity (Level 1)

- Demonstrate an understanding of how their own personal/cultural history, attitudes, and biases may affect how they understand and interact with people different from themselves.

- Integrate current theoretical and empirical knowledge of diversity issues in neuropsychological assessment, research, treatment, and consultation (e.g. health disparities, language differences, educational level, cultural context, literacy, individual differences); understand and appreciate how cultural, linguistic, disability, and other demographic/socioeconomic factors affect the process and outcomes of neuropsychological assessments and the application of normative data and interpretations in specific populations.

- Demonstrate the ability to integrate awareness and knowledge of individual and cultural differences in the conduct of professional roles (e.g., research, services, and other professional activities). This includes the ability to apply a framework for working effectively with areas of individual and cultural diversity not previously encountered over the course of their careers. Also included is the ability to work effectively with individuals whose group membership, demographic characteristics, or worldviews create conflict with their own.

Professional Identity \& Relationships/Self-Reflective Practice (Level 3)

- Possess knowledge of the varying roles of clinical neuropsychologists across settings (e.g., practice, research, training) and assessment/intervention contexts.

- Demonstrate professional behavior and comportment that reflects the values and attitudes of clinical neuropsychology.

- Maintain productive relationships with a variety of individuals and demonstrate effective interpersonal skills, including the ability to manage difficult communication well.

- Engage in reflective self-assessment regarding limits of competence (e.g., knowledge base and skill sets necessary for practice).

- Exhibit awareness of personal and professional problems and demonstrate positive coping strategies with personal and professional stressors and challenges.

Interdisciplinary Systems/Consultation (Level 3)

- Understand the key issues, concepts, and roles in related disciplines (e.g., neurology, psychiatry, neuroradiology, rehabilitation, and education) and other health professions, communicate effectively with other professionals, make appropriate referrals to them, and integrate their perspectives into case conceptualizations.

- Function effectively in consulting roles across settings (e.g., clinical, legal, public policy, research), clarifying referral questions, applying knowledge appropriate to each setting, and communicating results to referral sources both verbally and in writing.

Assessment (Level 3)

- In neuropsychological assessment, accurately discern and clarify assessment questions, including who will be the "consumers" of the assessment results, and how assessment results will be utilized. 
Table 12. (continued)

- Effectively gather information essential to addressing assessment questions, utilizing

o clinical interviews;

o targeted behavioral observations;

o records reviews;

o selection, administration, and scoring of neuropsychological tests appropriate to specific assessment contexts.

- Interpret assessment results to produce integrated conceptualizations, accurate diagnostic classifications, and useful recommendations.

- Communicate both orally and in written reports the results and conclusions of assessments in an accurate, helpful, and understandable manner, sensitive to a range of audiences.

- Address issues related to specific patient populations by referring to providers with specialized competence when appropriate, obtaining consultation, utilizing appropriate normative data, and describing limitations in assessment interpretation.

Intervention (Level 3)

- Understand evidenced-based intervention practices to address cognitive and behavioral problems present in different clinical populations.

- Understand how complex neurobehavioral disorders and sociocultural factors can affect the applicability of interventions.

- Employ assessment and provision of feedback for therapeutic benefit.

Research (Level 3)

- Accurately and effectively perform neuropsychological research activities, monitor progress, evaluate outcome, and communicate research findings.

- Apply knowledge of existing neuropsychological literature and the scientific method to generate appropriate research questions and determine effective research design and appropriate analysis.

Teaching/Supervision/Mentoring (Level 3)

- Demonstrate knowledge of teaching, supervision, and mentoring theories, methods, and practices relevant to clinical neuropsychology.

- Teach, supervise, and mentor related to clinical neuropsychology effectively and appropriately.

Management/Administration (Level 3)

- Possess knowledge of common administrative and business practices in neuropsychology practice (e.g., referral patterns, coding, billing, documentation).

- Manage responsibility for key patient care tasks and contacts with effective documentation in a timely manner.

Table 13. Target, purpose and audience for education and training documents in clinical neuropsychology

\begin{tabular}{|c|c|c|c|c|}
\hline Document & Applies to & $\begin{array}{l}\text { Intended audience (in } \\
\text { priority order) }\end{array}$ & Intended function & Not intended to: \\
\hline $\begin{array}{l}\text { Houston conference } \\
\text { guidelines (Hannay } \\
\text { et al., 1998) }\end{array}$ & Trainees & $\begin{array}{l}\text { Trainees } \\
\text { Credentialing } \\
\text { organizations } \\
\text { Training directors }\end{array}$ & $\begin{array}{l}\text { Describe training pathways for } \\
\text { clinical neuropsychology }\end{array}$ & $\begin{array}{l}\text { Specify individual } \\
\text { competencies }\end{array}$ \\
\hline Taxonomy & $\begin{array}{l}\text { Graduate programs, internships, post- } \\
\text { doctoral residencies, and continuing } \\
\text { education programs }\end{array}$ & $\begin{array}{l}\text { Training directors } \\
\text { Prospective trainees }\end{array}$ & $\begin{array}{l}\text { Standardize terminology across } \\
\text { training programs, training levels } \\
\text { and specialties }\end{array}$ & $\begin{array}{l}\text { Define education and } \\
\text { training standards } \\
\text { within a specialty } \\
\text { Define competence }\end{array}$ \\
\hline $\begin{array}{l}\text { Entry level competency } \\
\text { document }\end{array}$ & Individual neuropsychologists & $\begin{array}{l}\text { CRSPPP } \\
\text { Credentialing } \\
\text { organizations } \\
\text { Training directors, } \\
\text { neuropsychologists in } \\
\text { training }\end{array}$ & $\begin{array}{l}\text { Describe basic competence in } \\
\text { clinical neuropsychology. }\end{array}$ & $\begin{array}{l}\text { Define training pathway } \\
\text { (See Houston } \\
\text { Guideline for this) }\end{array}$ \\
\hline
\end{tabular}

and training in clinical neuropsychology should appear. These documents were developed at different times for different purposes, for different audiences. These distinctions are summarized in Table 13. It is unlikely that these documents will persist without modification for 20 more years. Indeed, the pace of specification and clarification in training models in professional psychology is increasing at the same time that the breadth and depth of neuropsychologists' professional activities are expanding. Proficiency with new technologies may increasingly be required. Challenges in assessing competencies may result in revisions of how they are specified. Subspecialty recognition may result in the need for distinctive training pathways and competencies. The need to iterate the documents included herein will be a great sign of the vitality of our profession.

\section{Conflict of interest}

None declared. 


\section{References}

American Psychological Association. (2009a). Association rules. Retrieved from http://www.apa.org/about/governance/bylaws/index.aspx.

American Psychological Association. (2009b). Guidelines and principles for accreditation of programs in professional psychology. Retrieved from http:// www.apa.org/ed/accreditation/about/policies/guiding-principles.pdf.

American Psychological Association, Commission on Accreditation. (2003). Implementing regulations: Section C. IRs related to the Guidelines and Principles. Retrieved from http://www.apa.org/ed/accreditation/about/policies/implementing-guidelines.pdf.

American Psychological Association, Commission on Accreditation. (2015). Standards of accreditation for health service psychology. Retrieved 3/1/2018 from http://www.apa.org/ed/accreditation/about/policies/standards-of-accreditation.pdf.

American Psychological Association. (2011). Principles for the recognition of a specialty in professional psychology. Retrieved 5/1/2017 from http://www. apa.org/about/policy/principles-recognition.pdf.

American Psychological Association. (2012). Education and training guidelines: A taxonomy for education and training in professional psychology health service specialties. Retrieved 11/27/2013 from http://www.apa.org/ed/graduate/specialize/taxonomy.pdf.

Epstein, R. M., \& Hundert, E. M. (2002). Defining and assessing professional competence. Journal of the American Medical Association, 287, $226-235$.

Hannay, J. H., Bieliauskas, L. A., Crosson, B. A., Hammeke, T. A., Hammsher, K. S., \& Koffler, S. P. (1998). Proceedings of the Houston conference on specialty education and training in clinical neuropsychology. Archives of Clinical Neuropsychology, 13, 157-250.

Health Service Psychology Education Collaborative. (2013). Professional psychology in health care services: A blueprint for education and training. American Psychologist, 68, 411-426.

Kaslow, N. J. (2004). Competencies in professional psychology. American Psychologist, 59, 774-781.

Kaslow, N. J., Borden, K. A., Collins, F. L., Forrest, L., Illfelder-Kaye, J., Nelson, P. D., et al. (2004). Competencies conference: Future directions in education and credentialing in professional psychology. Journal of Clinical Psychology, 80, 699-712.

Rey-Casserly, C., Roper, B. L., \& Bauer, R. M. (2012). Application of a competency model to clinical neuropsychology. Professional Psychology: Research and Practice, 43, 422-431.

Roberts, M. C., Borden, K. A., \& Christiansen, M. (2005). Toward a culture of competence: Assessment of competence in the education and careers of professional psychologists. Professional Psychology: Research and Practice, 36, 355-361.

Rodolfa, E. R., Bent, R. J., Eisman, E., Nelson, P. D., Rehm, L., \& Ritchie, P. (2005). A cube model for competency development: Implications for psychology educators and regulators. Professional Psychology: Research and Practice, 36, 347-354.

Sweet, J. J., Perry, W., Ruff, R. M., Shear, P. K., \& Guidotti Breting, L. M. (2012). The Inter-Organizational Summit on Education and Training (ISET) 2010 Survey on the influence of the Houston Conference Training Guidelines. The Clinical Neuropsychologist, 26, 1055-1076. (Published simultaneously in Archives of Clinical Neuropsychology).

Williams, B. C., Warshaw, G., Fabiny, A. R., Lundebjerg, N., Medina-Walpole, A., Sauvigne, K., et al. (2010). Medicine in the 21st Century: Recommended essential geriatrics competencies for internal medicine and family medicine residents. Journal of Graduate Medical Education, 2, 373-383. http://doi.org/ 10.4300/JGME-D-10-00065.1. 